\title{
Interest Consideration and Feasibility Analysis of Extending Mandatory Age for Retirement in China-Analysis based on the viewpoint of stakeholders
}

\author{
Xuefeng Zhang ${ }^{1}$, Yue Zhang ${ }^{2}$ \\ ${ }^{1}$ School of Political Science and Public Administration, Southwest University, Chongqing 400715,
China \\ ${ }^{2}$ School of Management, Chongqing Industry Polytechnic College, Chongqing, 401120, China
}

Keywords: Retirement age, Stakeholders, Feasibility

\begin{abstract}
It was clearly proposed in Decision for a number of major issues regarding comprehensively deepening the reform by CPC central committee issued in the third plenary session of the 18th central committee of CPC that "Study and formulate progressive extend retirement age policy”, and postponed retirement has been the major trend. This paper mainly stands at the perspective of stakeholders, trying to find a balance between different interested parties, and reach out the conclusion that postponed retirement is feasible.
\end{abstract}

\section{Introduction of current retirement age}

Retirement is a mandatory institutional arrangement, which confirms workers may be out of the labor force under a certain age and certain conditions and have the right to get appropriate economic income security [1]. Our retirement system has been through half a century of change since 1950s, except for some minor adjustments, the body has not had a big change, and it is divided into two parts: the general retirement system and the special retirement system.

Connotation of stakeholder theory. The word "stakeholder" first appeared in 1708's Oxford Dictionary, which represents the stake of people in an activity [2]. In 1963, Stanford Research Center (now called SRI) first proposed the concept of stakeholder, defined as "a group no longer exists without whose support" [3]. In 1984, strategic management expert Freeman gave the broad stakeholder a classic definition, namely "Stakeholders are individuals or groups to achieve the realization of business goals that can affect or are affected by corporate objectives." The core issue of stakeholder theory is twofold: First, who are the stakeholders, and second, how to divide the stakeholders [4]. After the 1990s, scholars from different countries conducted further study for the definition and classification of stakeholders. With the maturity of stakeholder theory, stakeholder analysis as an effective analytical tool, it is widely used in risk management and public administration. This article was interested stakeholders on the implementation of all the retirement age policy objectives and its groups and individuals have an impact.

\section{Analysis for stakeholders in postpone retirement age}

Regarding the classification of stakeholders, one method which is currently used widely is Mitchell score; its core is to look fit Stakeholders and relevance, urgency, influence three properties of potential stakeholders rating, score determines the level of an individual or group of stakeholders and whether it is related to the type. According to extend the retirement age stakeholders fit for the three properties, we classify stakeholders into the core stakeholders, marginal stakeholders and potential stakeholders. (Table 2.2)

Core stakeholders can be divided into strong core stakeholders and vulnerable stakeholders in accordance influence. Delay the retirement age in countries with policy development initiative, holds a lot of resources, it is a strong core stakeholders. And delay the retirement age of high relevance and urgency, but the influence of weak labor and business interests of disadvantaged stakeholders.

Marginal stakeholders are organizations and individuals with certain relevance and influence with postponed retirement age. Media as a link between government and the public communication, both 
collectors of information is transmitted by information between the government and the public to form a triangle interaction. Research institutions and scholars can provide professional advice to the government, to assess the feasibility of implementation of the system.

Potential stakeholders: means organizations and individuals with minor relevance, urgency and influence for public crisis.

Table 1. Analysis for stakeholders in postpone retirement age

\begin{tabular}{ccccc}
\hline Three categories & Stakeholders & Relevance & Urgency & Influence \\
\hline \multirow{3}{*}{ Core stakeholders } & Laborers & High & High & Medium $\rightarrow$ High \\
\cline { 2 - 5 } & $\begin{array}{c}\text { Enterprises } \\
\text { benefits }\end{array}$ & High & High & Medium $\rightarrow$ High \\
\cline { 2 - 5 } & Government & High & High & High \\
\hline $\begin{array}{c}\text { Marginal } \\
\text { stakeholders }\end{array}$ & Media & Medium & Medium & Medium \\
\cline { 2 - 5 } & $\begin{array}{c}\text { Research } \\
\text { institutions and } \\
\text { scholars }\end{array}$ & Medium & Medium & Medium $\rightarrow$ High \\
\hline $\begin{array}{c}\text { Potential } \\
\text { stakeholders }\end{array}$ & Bystanders & Low & Low & Low \\
\hline
\end{tabular}

\section{Feasibility analysis based on stakeholders}

\section{Individuals - limited influence on employment}

The emergence of the employment problem is mainly because of structural unemployment, inadequate job matching. The phenomenon of "Retirement Employment" explains widespread reason retirees can find a job, because there are job requirements in the market, delay the retirement age for employment status "crowding out" and has no direct effect. Also the elderly and youth employment, there is no absolute substitutes. In particular, some highly technical, the need for adequate mental experience, new labor force short time is difficult to replace. And if the retirement age is too low, retirees can be employed again, there is no vacant post. That is, the exit of older workers does not release the same amount of employment for young people to jobs from the total. Instead raising the retirement age, it will not only allow the elderly to continue to play a role in the post, standardized employment of the elderly, reducing people post does not match the phenomenon, increase social benefits, can bring some youth employment. With the development of the times, will have more and more work for the elderly, young people do not necessarily have the will and the skills to go off, so that the two are not perfectly competitive relationship. Professor Christopher A. Pissarides, who is the Nobel winner of economics in 2010 said: If older people work longer hours, they will be a corresponding increase in spending will create more job opportunities for young people and that "delay retirement to increase more jobs." [5]. Chinese Academy of Social Sciences, Institute of Population and Labor Economy Wei Zhang, deputy director also pointed out that the negative impact of delayed retirement age for employment mainly occurred at the beginning of the first years of implementation of this policy, but the negative impact will be with practice goes gradually weaken and disappear. And if you take the proper way to delay the retirement age, the impact will be smaller [6]. Also the other hand, some Western countries have taken the practice to shorten the retirement age has not achieved the desired effect is to reduce unemployment, but also on the other hand supports our views on the relationship between retirement age and unemployment.

\section{Enterprises - Will not weaken enterprise competitiveness}

Postponing retirement age does not conflict with enterprise economic target. Possible adverse effects of the retirement age for the delay caused by the impact just in time for different types of work to bring the positions corresponding good human resources planning, job setting reasonable 
adjustments, we can reduce its negative side, full use it brings a positive influence to enhance the competitiveness of enterprises as a whole.

\section{Government - Remit pension payment pressure}

China's current pension system belongs to young retirees with respect to the situation in terms of average life expectancy, a large number of workers out of production areas directly reduce the number of pension contributions, reduced pension income scale. While younger retirees change into pensions enjoyer from pension contributors, a direct result of greatly increasing the size of pension expenditure. The current retirement system therefore resulting reduction in revenue multiverse greatly increased the burden on the pension. Conversely, if the retirement age can increase the number of contributions and the payment period to increase pension income at the same time the number of years of pension payments reduced pension expenses also decreased, so as to achieve a fiscal balance, reduce pension payments gap, is conducive to long-term operation of pension funds, to meet the challenges posed by aging provide effective protection. Of course, as a livelihood policy, delays in the development of the retirement age, not only to consider the interests of the state, the collective aspects, but also to the individual as a social worker to have a certain degree of tilt. Only the system with full consideration and protection of the interests of workers on the basis of implementation, it is practical.

\section{Suggestions for approaches to extend retirement age}

\section{Establish complete interest expression mechanism}

Whether a reform is successful, the key involves that does it fully consider the interests of different groups, truly fair. From the opening of the legitimacy of the policy and the transparency of its procedures, and therefore cannot make just one voice into the decision-makers perspective, to seriously listen to opinions from all sides, public opinion cannot be "selective filter."

A good public policy should be representative of the majority of the public interest, the key lies in the policy-making process to the public to actively participate in a wide range, to build a sound mechanism to express interest. First, the formula should be adopted to improve the social system, the public administration system, the petition system, to ensure that the public expression of interest rules to follow. Secondly, there is a clear expression of interest channels, particularly vulnerable groups express interest channels open, while focusing on networking, social polls functions. Finally, interest demands reasonable integration to the interests of most people-oriented.

Postponing retirement age is related to the interests of all sectors of society, and thus in the formulation of policy, not only consider one aspect or an interest group. For the delay retirement age may bring negative aspects or interest groups may hurt to listen to their opinions, to present identity as losers provides alternatives to relieve their doubts, the implementation of the delayed retirement age resistance becomes the driving force. As long as the policy put in the "sunshine" discussion, which fully reflects the public's awareness of ownership, and find a solution in the best interests of coordination.

\section{Complete social security system and laws and regulations}

Retirement system reform involves pension, employment and other issues, which is a comprehensive reform. So, while the retirement age should be reformed or related coordination, ensure that the entire reform really achieve the desired effect. Different positions, different forms of pension decision and some people will welcome the delay retirement age, some people will oppose the core of the problem is that these differences are now pension system itself, there are unfair. The employment of workers at the workplace zoned for businesses and institutions, and follows to the pension insurance, PSU employees after retirement pensions by the state government budget, while staff pension business units by the time employment to pay their to determine its level of pensions, so he caused the institutions of retired workers' pensions of retired workers is much higher than the status of enterprise units. 
The two-track system of pension benefits allows the differentiated pension treatment retirement continues to enlarge age in the process of postponing retirement, resulting in greater injustice. Organs and institutions "within the institutional advantages" Reducing the general corporate employees of labor enthusiasm and confidence in the Social Security System pension fund, while trying to delay the retirement age in order to encourage the public manner in the implementation of it meaningless. Delayed retirement age is "the world community", but public acceptance delay retirement age, more than just retirement practice. In foreign countries, whether civil servants or enterprise employees, or members of the public or farmer, as long as the legal retirement age, the same can receive a basic pension. Moreover, China's two-track pension significantly enhanced public sentiment against delay the retirement age. Implementation delay retirement policy on the premise that the establishment of a unified social security system, so in order to ensure smooth implementation delay retirement, it is necessary to solve the pension dual-track system, so that a variety of institutional units, employees in various capacities, can enjoy equal pension Gold collection and payment system, in the same platform, the same runway competition and promote equitable pensions of all workers, eliminate laborers from unfair system and delay the retirement age of the main exclusion.

The abolition of "two track system" not only has a negative effect for the implementation of retirement age postponing, but also can increase pension income, to ease pressure on the payment of pensions. China has about 47 million people do not pay pension insurance, pension after retirement but also pay more than the old-age insurance, they owed a year's pension is 658 billion yuan, accounting for $39 \%$ of the total collection of pension insurance. If the abolition of "dual system", China's pension funds accounts will be greatly enriched [7]. Therefore, the abolition of "two track system" is a focus of current reform.

\section{Reinforce supervision; prevent retirement system "value anomie"}

Public policy "value anomie" refers to public policy deviates from the target during execution (this target can be summarized as to achieve the overall interests of the community at the core of public interest maximization), and becomes the tool for a minority of persons or a privileged group for seeking interests[8]. The reason why postponing retirement age get people's favor because the it can get more benefits, but if such an interest obtained is based on the damage the interests of others, deviation from policy to achieve the original goal of social equity, then such a reform is bound to be the opposition of others, but also lost the meaning of implementation.

In order to prevent postponing retirement age system "value anomie", it is necessary to establish interest monitoring system in the implementation process of postponing retirement age, to smooth channels of social supervision, to collect information on interest flows, benefit stakeholders and conduct damage investigation and analysis, timely adjustment of policy implementation deviates from the original target of the phenomenon.

Postponing retirement age is proposed in the context of serious aging population and large gap of pension, which is consistent with the historical and social development. But you can see the retirement age is a complex, involving a wide range of policy, especially in our area a big difference this populous country, so when designing must be in line with our reality, in line with China's population structure and labor the reality of supply and demand, classification progressively push to delay retirement policy. Do pay close attention to the comprehensive study, listen, respond to the concerns, strict procedures, and the balance of interests, careful decision making steady and truly beneficial to the people, socially beneficial, beneficial to the country.

\section{Acknowledgments}

This paper is sponsored by Southwest University School of Political Science and Public Administration young and middle-aged project.

\section{References}

[1] Shi Bonian et al, Social insurance theory. Higher Education Publishing House, 2004 
[2] Li Zhen, Empirical analysis regarding retirement age in China. China Social Insurance, 1998, (04)

[3] Jia Shenghua, Chen Honghui, Definition method of stakeholder review. Foreign Economy and Management, 2002, 24(5).

[4] R. Edward. Freeman, Strategic Management: Method of Stake holders. Translated by Wang Yanhua, Liang Hao. Shanghai: Shanghai Translation Publishing House, 2006.30

[5] Xiao Gang, Zhang Shutong, Nobel Prize winner: postponed retirement can remit employment. Chengdu Commercial Daily, 2012.9.18

[6] Zhang Chewei: gradual model postponed retirement has minor impact on youth's employment. China broadcasting network

[7] Liu Zhirong, Calculate postponed retirement cost accounts. Human Resources. 2013.7

[8] Wang Li, Wang Zheng, Wang Yongmei, Interest consideration in public policy- analysis based on stake holder theory. Management Science. 2012, (4) 